\title{
The effects of a high protein diet on indices of health and body composition - a crossover trial in resistance-trained men
}

\author{
Jose Antonio ${ }^{*}$, Anya Ellerbroek, Tobin Silver, Leonel Vargas and Corey Peacock
}

\begin{abstract}
Background: Eight weeks of a high protein diet ( $>3 \mathrm{~g} / \mathrm{kg} /$ day) coupled with a periodized heavy resistance training program has been shown to positively affect body composition with no deleterious effects on health. Using a randomized, crossover design, resistance-trained male subjects underwent a 16-week intervention (i.e., two 8-week periods) in which they consumed either their normal (i.e., habitual) or a higher protein diet ( $>3 \mathrm{~g} / \mathrm{kg} /$ day). Thus, the purpose of this study was to ascertain if significantly increasing protein intake would affect clinical markers of health (i.e., lipids, kidney function, etc.) as well as performance and body composition in young males with extensive resistance training experience.

Methods: Twelve healthy resistance-trained men volunteered for this study (mean \pm SD: age $25.9 \pm 3.7$ years; height $178.0 \pm 8.5 \mathrm{~cm}$; years of resistance training experience $7.6 \pm 3.6$ ) with 11 subjects completing most of the assessments. In a randomized crossover trial, subjects were tested at baseline and after two 8-week treatment periods (i.e., habitual [normal] diet and high protein diet) for body composition, measures of health (i.e., blood lipids, comprehensive metabolic panel) and performance. Each subject maintained a food diary for the 16-week treatment period (i.e., 8 weeks on their normal or habitual diet and 8 weeks on a high protein diet). Each subject provided a food diary of two weekdays and one weekend day per week. In addition, subjects kept a diary of their training regimen that was used to calculate total work performed.
\end{abstract}

Results: During the normal and high protein phase of the treatment period, subjects consumed $2.6 \pm 0.8$ and $3.3 \pm 0.8 \mathrm{~g} / \mathrm{kg} /$ day of dietary protein, respectively. The mean protein intake over the 4-month period was $2.9 \pm 0.9 \mathrm{~g} / \mathrm{kg} /$ day. The high protein group consumed significantly more calories and protein $(p<0.05)$ than the normal protein group. There were no differences in dietary intake between the groups for any other measure. Moreover, there were no significant changes in body composition or markers of health in either group. There were no side effects (i.e., blood lipids, glucose, renal, kidney function etc.) regarding high protein consumption.

Conclusion: In resistance-trained young men who do not significantly alter their training regimen, consuming a high protein diet (2.6 to $3.3 \mathrm{~g} / \mathrm{kg} /$ day) over a 4-month period has no effect on blood lipids or markers of renal and hepatic function. Nor were there any changes in performance or body composition. This is the first crossover trial using resistance-trained subjects in which the elevation of protein intake to over four times the recommended dietary allowance has shown no harmful effects.

Keywords: Protein, Diet, Body composition, Nutrition, Body fat

\footnotetext{
* Correspondence: ja839@nova.edu

Exercise and Sports Sciences, Nova Southeastern University, 3532 S.

University Drive, University Park Plaza Suite 3532, Davie, FL 33314, USA
} 


\section{Background}

There is a dearth of studies that have examined the effects of high protein diets on markers of health, body composition or performance. The International Society of Sports Nutrition's Position Stand on Protein states that "protein intakes of $1.4-2.0 \mathrm{~g} / \mathrm{kg} /$ day for physically active individuals is not only safe, but may improve the training adaptations to exercise training" [1]. Previous work from our laboratory examined a true high protein diet $(4.4 \mathrm{~g} / \mathrm{kg} /$ day $)$ on measures of body composition and performance. In essence, consuming over five times the recommended daily allowance of protein had no effect on body composition in resistance-trained individuals who otherwise maintained the same training regimen. That investigation was the first interventional study to demonstrate that consuming a hypercaloric, high protein diet does not result in changes in body composition [2]. A follow-up investigation on resistancetrained men and women found that when a high protein diet is combined with a periodized heavy resistance training program, there is a subsequent loss of fat mass. Furthermore, no side effects were found via a basic metabolic panel (i.e., blood chemistry measures). Thus, the purpose of the present investigation was to determine the effects of a high protein diet $(>3 \mathrm{~g} / \mathrm{kg} /$ day $)$ in resistance-trained males with extensive weight-training experience. This is the first randomized, crossover trial on high protein diets. In addition, we have performed a more extensive examination of its effects on other markers of metabolic health (i.e., blood lipids and comprehensive metabolic panel).

\section{Methods}

\section{Participants}

Twelve resistance-trained male subjects volunteered for this investigation. Subjects took part in a randomized crossover trial in which they consumed their habitual (i.e., normal protein) or high protein diet for two 8-week periods. Thus, there was a total treatment period of 16 weeks (i.e., 8 weeks on normal or high followed by 8 weeks on the opposite diet). Subjects came to the laboratory on three occasions: baseline, week 8 and week 16. The extra protein consumed by each subject was obtained primarily from whey protein powder. All procedures involving human subjects were approved by Nova Southeastern University's Human Subjects Institutional Review Board in accordance with the Helsinki Declaration and written informed consent was obtained prior to participation.

\section{Food diary}

Subjects kept a diary (i.e., three days per week for the 16 week period; two weekdays and one weekend day) of their food intake via a smartphone app (MyFitnessPal $\left.{ }^{\circ}\right)$.
The use of mobile apps for dietary self-reporting has been previously used [3]. Every subject had previously used this mobile app. The MyFitnessPal ${ }^{\circ}$ app is a database comprised of over 5 million foods that have been provided by users via entering data manually or by scanning the bar code on packaged goods. Thus, the data themselves are primarily derived from food labels (i.e., Nutrition Facts Panel) derived from the USDA National Nutrient database. Thus, in order for subjects to consume a high protein diet, protein powder (e.g., whey protein) was provided at no cost to the research subjects. However, they were not required to consume protein powder. The rest of their dietary protein was obtained from their regular food intake.

\section{Body composition}

Height was measured using standard anthropometry and total body weight was measured using a calibrated scale. Body composition was assessed by whole body densitom-

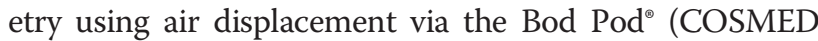
USA, Concord CA). All testing was performed in accordance with the manufacturer's instructions. Subjects were instructed to come into the lab after a 3-h fast and no exercise 24-h prior. They voided prior to testing. Subjects were tested while wearing only tight fitting clothing (swimsuit or undergarments) and an acrylic swim cap. Subjects were instructed to wear the same clothing for all testing. Thoracic gas volume was estimated for all subjects using a predictive equation integral to the Bod $\mathrm{Pod}^{\circ}$ software. Each subject was tested at least twice per visit. The calculated value for body density used the Siri equation to estimate body composition. Data from the Bod $\mathrm{Pod}^{\circledR}$ include body weight, percent body fat, fat free mass and fat mass. All testing was done with each subject at approximately the same time of day for each of the three testing sessions. Although hydration status was not assessed, each subject was tested in an identical manner throughout the investigation. The Bod Pod was calibrated the morning of the testing session as well as between each subject.

\section{Performance testing}

Performance testing included the one repetition maximum (1-RM) bench press and repetitions to failure (RTF) at $60 \%$ of the bench press 1-RM. Performance tests were conducted by certified strength and conditioning specialists and followed the NSCA's guide to tests and assessments [4]. All subjects were familiar with the performance tests prior to entering the laboratory. In general, each subject performed a movement specific warm up prior to the test (i.e., 3 sets on the bench press at progressively higher submaximal loads). Subjects then rested for 2-3 min prior to commencing the 1-RM bench press. A maximum of five attempts was attempted for the 1-RM bench press. Once the subject achieved 
their 1-RM, they rested for 3-5 min prior to commencing the RTF at $60 \%$ of the 1-RM bench press. The maximal number of repetitions was subsequently determined.

\section{Blood analysis - comprehensive metabolic panel and blood lipids}

Subjects presented after an overnight fast at a local Quest Diagnostics $^{\mathrm{TM}}$ facility on three separate occasions. A blood lipid and comprehensive metabolic panel was done. This includes the following measures: glucose, blood urea nitrogen (BUN), creatinine, glomerular filtration rate, BUN/creatinine ratio, sodium, potassium, chloride, carbon dioxide, calcium, total protein, albumin, globulin, albumin/globulin ratio, total bilirubin, alkaline phosphatase, alanine transaminase, asparate transaminase, total cholesterol, high density lipoprotein cholesterol, triglycerides, low density lipoprotein cholesterol and the total cholesterol to high density lipoprotein cholesterol ratio. Quest Diagnostics performed each test according to the standard operating procedure of the company.

\section{Training program}

Each subject followed their own strength and conditioning program. The investigators were in regular contact with each subject to ensure that each subject completed a training log. The volume load (i.e., total weight lifted per week) was determined for each 8-week period.

\section{Statistics}

A 2-way analysis of variance (ANOVA) was used to analyze the data with a $p<0.05$ considered significant. Data are expressed as the mean \pm SD. The statistical analysis was completed using Prism 6 GraphPad Software (La Jolla California).

\section{Results}

The characteristics of the 12 male subjects in this investigation were as follows: [Mean $\pm \mathrm{SD}$ ]: age $25.9 \pm 3.7$ years; height $178.0 \pm 8.5 \mathrm{~cm}$; years of resistance training experience $7.6 \pm 3.6$. We did not conduct normality of data measures.

\section{Body composition and performance}

Body composition and performance data are presented in Table 1 and Figs. 1, 2 and 3 (i.e., individual changes in fat mass, FFM and \% body fat). There were no significant differences between the normal and high protein groups for any of the measures.

\section{Diet}

There were significant differences in total energy and protein intake between the high protein, normal protein
Table 1 Body composition and performance

\begin{tabular}{llll}
\hline & Baseline & Normal protein & High protein \\
\hline Weight kg & $85.24 \pm 10.83$ & $84.43 \pm 10.58$ & $83.98 \pm 10.63$ \\
Fat Mass kg & $12.07 \pm 3.23$ & $12.04 \pm 3.36$ & $10.97 \pm 2.89$ \\
Fat Free Mass kg & $73.17 \pm 9.83$ & $72.39 \pm 8.50$ & $73.00 \pm 9.93$ \\
\% Body Fat & $14.19 \pm 3.32$ & $14.15 \pm 2.80$ & $13.13 \pm 2.98$ \\
Bench Press & $126.4 \pm 13.9$ & $119.2 \pm 17.7$ & $122.3 \pm 13.1$ \\
$\begin{array}{l}\text { 1-RM kg } \\
\text { RTF at 60 \% }\end{array}$ & $19.9 \pm 3.2$ & $21.3 \pm 5.5$ & $21.9 \pm 3.0$ \\
1-RM BP & & & \\
Volume Load kg & $48,783 \pm 19,506$ & $50,578 \pm 18,881$ & $48,989 \pm 15,388$
\end{tabular}

Data are mean \pm SD. $n=11$ (one subject's body composition data was incomplete)

$B P$ bench press, $\mathrm{kg}$ kilograms, RTF repetitions to failure

a Volume Load is calculated as the total amount of weight lifted per week (i.e., repetitions $\mathrm{x}$ weight for each set). ${ }^{\mathrm{b}} \mathrm{N}=7$ (four subjects could not do the exercise tests due to overuse injuries)

group and baseline (high $>$ normal and baseline; $p<0.05$ ) (Table 2). The mean percentage of macronutrients (CHO:PRO:Fat) were as follows: Baseline - 37:34:29, Normal - 34:36:30 and High - 30:42:28 (Fig. 4).

\section{Blood analysis}

There were no changes in any of the variables regarding blood lipids and a comprehensive metabolic panel (Tables 3 and 4). We examined the two individuals with the highest recorded protein intakes (4.66 and $6.59 \mathrm{~g} / \mathrm{kg} /$ day) and found no deleterious effects on renal function in either individual (Table 5).

\section{Discussion}

This is the third investigation from our laboratory that has examined the effects of a high protein diet (i.e., > $2 \mathrm{~g} / \mathrm{kg} /$ day). Previously published work has shown that consuming a high protein diet $(4.4 \mathrm{~g} / \mathrm{kg} /$ day $)$ does not significantly affect body composition (i.e., no statistically significant change in FFM, fat mass or \% body fat) in trained individuals who do not substantially change their exercise regimen [2]. On the other hand, a follow-up study found that a high protein diet $(3.4 \mathrm{~g} / \mathrm{kg} / \mathrm{d})$ in conjunction with a periodized heavy resistance training program can favorably alter body composition [5]. It should be noted that although the previous investigation used resistance-trained subjects, training experience varied greatly. The current study used only highly experienced resistance-trained males (i.e., $\sim 8$ years of training experience with a mean 1-RM bench press of $126 \mathrm{~kg}$ ). They could lift on average $\sim 1.5$ times their body weight. The subjects in the current study also had more than twice the resistance training experience as those in our prior investigation [5].

Similar to our first investigation [2], the current study found no statistically significant effects of a high protein 


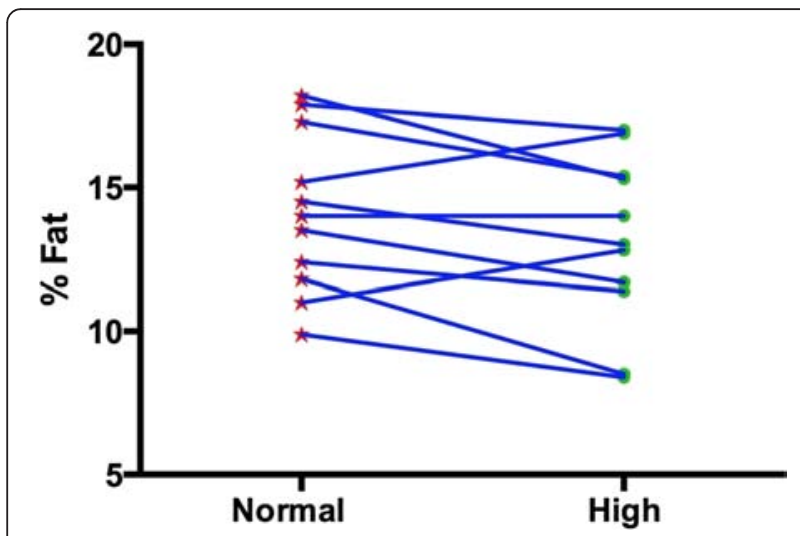

Fig. 1 Individual changes in body fat percentage

diet on body composition, 1-RM bench press strength or muscular endurance (RTF at $60 \%$ of the 1-RM bench press) when compared to the normal protein group. Although our subjects consumed approximately 400 additional calories daily for eight weeks, there were no significant changes in fat mass despite the fact that there were no changes in their exercise regimen.

With highly trained subjects, it is important that one examine individual data points. Nine of 11 subjects demonstrated a decrease in fat mass during the high protein diet phase. Two subjects showed an increase in fat mass. Relying on mean changes, particularly for trained subjects, is not an ideal way to understand the adaptive response to diet and/or exercise. Both mean and individual data points provide a much clearer picture of how high protein intakes affect various measures. Certainly, the small sample size (i.e., the study was underpowered) is likely the reason for the lack of statistical significance regarding fat mass. Nevertheless, the intriguing finding in the current study is that overfeeding on protein does not typically have an adverse effect on body composition.

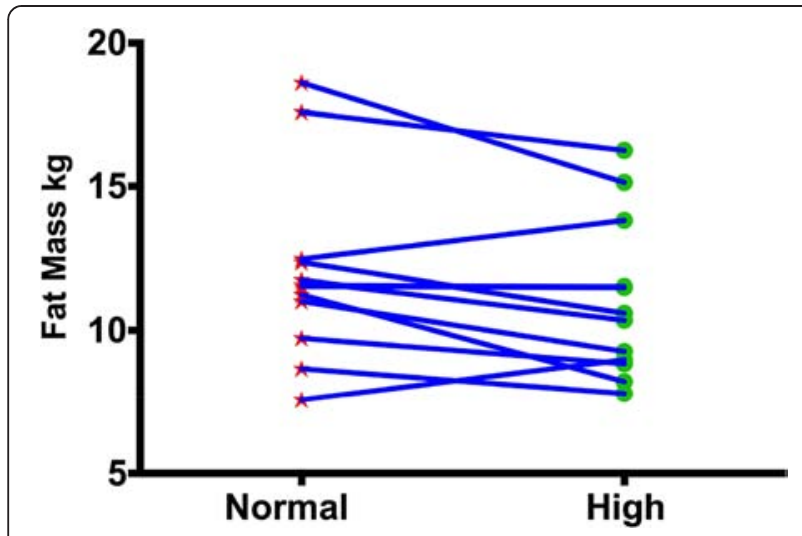

Fig. 2 Individual changes in fat mass

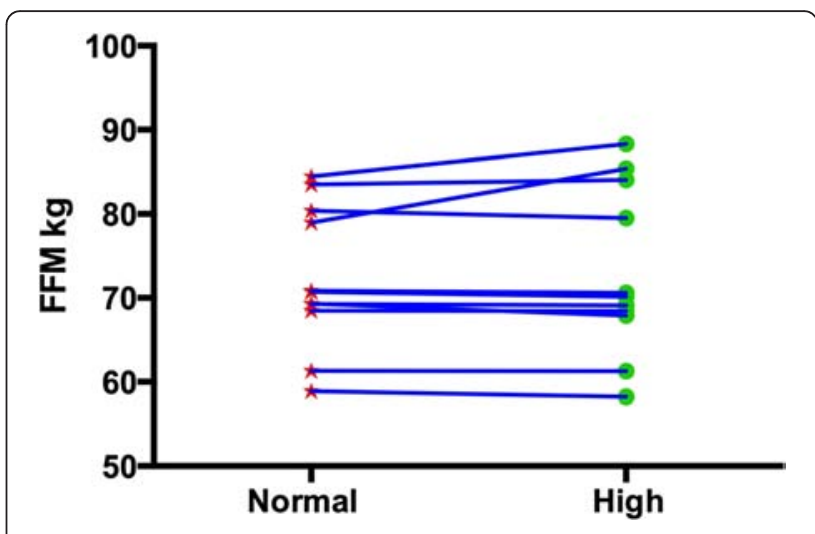

Fig. 3 Individual changes in fat free mass

The possible explanations for the lack of weight gain in our subjects include the following: changes in the thermic effect of exercise (TEE) as well as non-exercise activity thermogenesis (NEAT) might account in part for the slight decrease in percent body fat in the high protein diet group $[6,7]$. Ostensibly, NEAT can vary by as much as 2000 cal between individuals [7]. Thus, it is possible that in our group of well-trained subjects, NEAT could account for some of the additional energy expenditure. In addition to NEAT, dietary protein itself has profound thermic effect. Protein's thermic effect of feeding (TEF) is 19-23\% in both obese and lean individuals whereas carbohydrate is approximately 12-14\% [8]. A high protein diet (45\% total kcal) elicits a $30 \%$ greater TEF than an isocaloric low protein (15\% total $\mathrm{kcal}$ ) in active females [9]. The subjects in our study did

Table 2 Dietary intake

\begin{tabular}{lccl}
\hline & Baseline & Normal protein & High protein \\
\hline Kcal & $2453 \pm 352$ & $2534 \pm 343$ & $2903 \pm 415^{* \#}$ \\
CHO g & $226 \pm 81$ & $220 \pm 65$ & $219 \pm 78$ \\
PRO g & $190 \pm 76$ & $212 \pm 65$ & $271 \pm 61^{* \#}$ \\
Fat g & $80 \pm 27$ & $86 \pm 28$ & $88 \pm 16$ \\
Kcal/kg/day & $30.4 \pm 7.3$ & $31.6 \pm 7.5$ & $35.0 \pm 4.6^{*}$ \\
CHO g/kg/day & $2.7 \pm 1.0$ & $2.6 \pm 1.0$ & $2.7 \pm 1.0$ \\
PRO g/kg/day & $2.3 \pm 1.0$ & $2.6 \pm 0.8$ & $3.3 \pm 0.8^{* \#}$ \\
Fat g/kg/day & $1.0 \pm 0.4$ & $1.1 \pm 0.4$ & $1.0 \pm 0.2$ \\
Cholesterol mg/day & $542 \pm 359$ & $464 \pm 285$ & $780 \pm 566$ \\
Sodium mg/day & $2892 \pm 1125$ & $3175 \pm 971$ & $3484 \pm 766$ \\
Sugars g/day & $49 \pm 33$ & $50 \pm 27$ & $63 \pm 21$ \\
Fiber g/day & $27 \pm 16$ & $27 \pm 18$ & $30 \pm 12$ \\
\hline
\end{tabular}

Data are mean \pm SD. $n=12$

CHO carbohydrate, $P R O$ protein, $g$ grams, $k g$ kilograms, $d$ days, HP high protein, NP normal protein

${ }^{*} P<0.05$ - denotes significantly different than baseline. ${ }^{\#} P<0.05$ - denotes significantly different than normal protein 


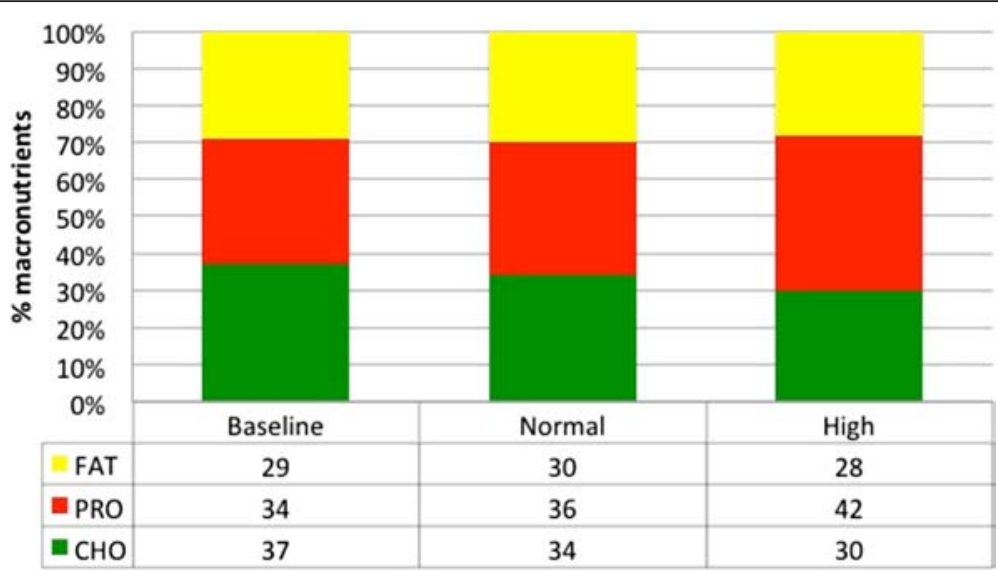

Fig. 4 The Macronutrient percentages of each group

not alter fat or carbohydrate intake; thus, that could not be an explanation for changes in body composition. Thus, one might speculate that the high protein diet group experienced a combination of enhanced TEF, TEE and NEAT. Furthermore, recent animal data suggest that a high-protein diet might reduce fat mass by inhibiting lipogenesis in the liver [10].

In conjunction with our prior work, we further examined blood lipids as well as other markers of health. We found no deleterious effects of high protein consumption. There were no changes in blood lipids as well as renal or hepatic function. On average, subjects in this investigation consumed $\sim 3 \mathrm{~g}$ of protein per kilogram of body weight daily for four months. In fact, the subjects with the two highest levels of protein intake showed no changes in renal function despite exceeding the RDA by $483-724 \%$. Thus, it is evident that even at very high protein intakes, there are no harmful side effects.

It is worth noting that the fiber intake of our subjects was 27-30 g per day. The average fiber intake in the United States is $16 \mathrm{~g}$ per day [11]. Therefore, the notion that a high protein diet and adequate fiber consumption

Table 3 Comprehensive metabolic panel

\begin{tabular}{|c|c|c|c|c|}
\hline & Baseline & Normal protein & High protein & Reference range \\
\hline Glucose mg/dL & $83 \pm 12$ & $85 \pm 14$ & $84 \pm 19$ & $65-99$ \\
\hline BUN mg/dL & $22 \pm 5$ & $23 \pm 5$ & $23 \pm 6$ & $7-25$ \\
\hline Creatinine $\mathrm{mg} / \mathrm{dL}$ & $1.1 \pm 0.2$ & $1.1 \pm 0.1$ & $1.1 \pm 0.2$ & $0.60-1.35$ \\
\hline eGFR ml/min/1.73 m2 & $96 \pm 20$ & $102 \pm 18$ & $101 \pm 18$ & $\S$ \\
\hline BUN/Creatinine ratio & $19.4 \pm 5.4$ & $21.2 \pm 4.5$ & $20.5 \pm 2.8$ & $6-22$ \\
\hline Sodium mmol/L & $139 \pm 2$ & $138 \pm 2$ & $138 \pm 1$ & $135-146$ \\
\hline Potassium mmol/L & $4.3 \pm 0.4$ & $4.2 \pm 0.3$ & $4.3 \pm 0.2$ & $3.5-5.3$ \\
\hline Chloride $\mathrm{mmol} / \mathrm{L}$ & $103 \pm 2$ & $102 \pm 1$ & $102 \pm 3$ & $98-110$ \\
\hline Carbon Dioxide mmol/L & $27 \pm 2$ & $27 \pm 4$ & $27 \pm 2$ & $19-30$ \\
\hline Calcium mg/dl & $9.7 \pm 0.2$ & $9.6 \pm 0.3$ & $9.6 \pm 0.3$ & $8.6-10.3$ \\
\hline Total Protein g/dL & $7.2 \pm 0.4$ & $7.2 \pm 0.3$ & $7.1 \pm 0.4$ & $6.1-8.1$ \\
\hline Albumin $\mathrm{g} / \mathrm{dL}$ & $4.7 \pm 0.2$ & $4.6 \pm 0.2$ & $4.6 \pm 0.3$ & $3.6-5.1$ \\
\hline Globulin g/dL & $2.5 \pm 0.3$ & $2.6 \pm 0.3$ & $2.6 \pm 0.3$ & $1.9-3.7$ \\
\hline Albumin/Globulin ratio & $1.9 \pm 0.2$ & $1.8 \pm 0.2$ & $1.8 \pm 0.2$ & $1.0-2.5$ \\
\hline Total Bilirubin mg/dL & $0.7 \pm 0.3$ & $0.7 \pm 0.2$ & $0.7 \pm 0.3$ & $0.2-1.2$ \\
\hline Alkaline Phosphatase U/L & $65 \pm 17$ & $66 \pm 20$ & $65 \pm 16$ & 40-115 \\
\hline AST U/L & $28 \pm 9$ & $27 \pm 6$ & $27 \pm 6$ & $10-40$ \\
\hline ALT U/L & $29 \pm 19$ & $27 \pm 9$ & $28 \pm 10$ & $9-46$ \\
\hline
\end{tabular}

Data are mean \pm SD. $n=12$. ALT alanine transaminase, AST aspartate transaminase, BUN blood urea nitrogen, eGFR estimated glomerular filtration rate ( $\S$ normal values: $\geq 60 \mathrm{ml} / \mathrm{min} / 1.73 \mathrm{~m}^{2}$ ). There were no differences between any of the groups 
Table 4 Lipid panel

\begin{tabular}{lcccc}
\hline & Baseline & Normal protein & High protein & Reference range \\
\hline Total Cholesterol mg/dL & $161 \pm 30$ & $143 \pm 24$ & $152 \pm 31$ & $125-200$ \\
HDL Cholesterol mg/dL & $48 \pm 16$ & $46 \pm 20$ & $48 \pm 11$ & $\geq 40$ \\
Triglycerides mg/dL & $64 \pm 18$ & $57 \pm 25$ & $64 \pm 28$ & $<150$ \\
LDL Cholesterol mg/dL & $100 \pm 36$ & $86 \pm 26$ & $91 \pm 26$ & $<130$ \\
CHOL/HDL-C ratio & $4.1 \pm 3.2$ & $4.4 \pm 4.5$ & $3.2 \pm 0.7$ & $\leq 5.0$ \\
\hline
\end{tabular}

Data are mean \pm SD. $n=12$. There were no differences between any of the groups

is mutually exclusive is not supported by our data. One might speculate the combination of higher protein and fiber intake might assist in promoting fat loss [12]. Thus, the fact that our subjects were healthy (i.e., blood lipids, renal and hepatic function, etc.) may have been due partially to their fiber intake. It is known that higher fiber intakes are associated with a lower risk of cardiovascular disease [13]. Furthermore, the cholesterol intake of our subjects were as much as $160 \%$ greater than the typical recommendation of $300 \mathrm{mg}$ per day [14]. Thus it is apparent that in this select sample of highly trained males, cholesterol intake has little effect on blood measures of cardiovascular health.

The strengths of our investigation included the use of highly trained subjects and the fact that we used a crossover design. Thus, each subject could be compared to himself. The small sample size as well as the lack of control for the training program are certainly confounding variables. Also, we did not ascertain the hydration status of each subject. This could indeed affect our body composition assessment [15]. It is known that there may be a decrease in FFM if the subject went from a hydrated to a dehydrated state. To insure that this was minimized, we did follow identical pre- and post-testing body composition procedures.

\section{Conclusion}

In conclusion, this is the first randomized crossover trial in resistance-trained subjects that examined the effects of consuming a high protein diet over the course of several months on markers of performance, health and body composition. This study as well as previous work from our lab suggests that gains in body fat are unlikely to occur with protein overfeeding in conjunction with an increase in total energy intake [2].

Limitations of this study include the use of dietary self-reports. It has been posited that underreporting of dietary intake is a severe confounding variable in studies that involve a dietary intervention. Interestingly, this is not a universal finding. American women consistently underreport their caloric intake in contrast with only $10 \%$ of Egyptian women [16]. Novotny et al. found that that a sex difference existed in underreporting (i.e., women underreport more than men) [17]. Much of the additional protein consumed by the subjects in the current study was in the form of protein powder; therefore it would seem reasonable to assume that our male subjects could provide an accurate dietary recall with such a simple dietary addition. Furthermore, from an entirely pragmatic perspective, the use of dietary recalls is the best option to assess food intake in free-living

Table 5 Case reports - renal function on two subjects with the highest protein intakes

\begin{tabular}{|c|c|c|c|c|}
\hline & Baseline & Normal protein & High protein & Reference range \\
\hline \multicolumn{5}{|l|}{ Subject 1} \\
\hline PRO intake $\mathrm{g} / \mathrm{kg} / \mathrm{d}$ & 3.98 & 4.18 & 6.59 & $724 \%>$ than the RDA \\
\hline BUN mg/dL & 25 & 34 & 14 & $7-25$ \\
\hline Creatinine $\mathrm{mg} / \mathrm{dL}$ & 1.26 & 1.09 & 0.96 & $0.60-1.35$ \\
\hline eGFR ml/min/1.73 m2 & 88 & 105 & 122 & $\S$ \\
\hline BUN/Creatinine ratio & 19.8 & 31.2 & 14.6 & $6-22$ \\
\hline \multicolumn{5}{|l|}{ Subject 2} \\
\hline PRO intake $\mathrm{g} / \mathrm{kg} / \mathrm{d}$ & 2.56 & 3.61 & 4.66 & $483 \%>$ than the RDA \\
\hline BUN mg/dL & 22 & 26 & 20 & $7-25$ \\
\hline Creatinine mg/dL & 0.97 & 0.97 & 1.02 & $0.60-1.35$ \\
\hline eGFR ml/min/1.73 m2 & 125 & 126 & 119 & $\S$ \\
\hline BUN/Creatinine ratio & 22.7 & 26.8 & 19.6 & $6-22$ \\
\hline
\end{tabular}

Data are mean \pm SD. BUN blood urea nitrogen, eGFR estimated glomerular filtration rate ( $\S$ normal values: $\geq 60 \mathrm{ml} / \mathrm{min} / 1.73 \mathrm{~m}{ }^{2}$ ), $P R O \mathrm{protein}, R D A$ recommended dietary allowance 
individuals. Future work should examine very highly trained athletes who undergo cycles of varying protein intake over a period of several months or years. This would at least provide information in terms of whether the highly trained respond more so to a change in training stimulus, diet or a combination of both.

\section{Competing interests}

All authors have declared no competing interests or financial interests concerning the outcome of this investigation.

\section{Authors' contributions}

The study was designed by JA. Data were collected by AE, JA, CP, TS and LV. Data interpretation was undertaken by JA, CP and TS. Manuscript preparation was performed by JA, TS and CP. All authors approved the final version of this paper.

\section{Received: 28 October 2015 Accepted: 12 January 2016}

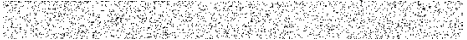

\section{References}

1. Campbell B, Kreider RB, Ziegenfuss T, La Bounty P, Roberts M, Burke D, et al. International Society of Sports Nutrition position stand: protein and exercise. J Int Soc Sports Nutr. 2007:4:8.

2. Antonio J, Peacock CA, Ellerbroek A, Fromhoff B, Silver T. The effects of consuming a high protein diet (4.4 g/kg/day) on body composition in resistance-trained individuals. J Int Soc Sports Nutr. 2014;11:19.

3. Turner-McGrievy GM, Beets MW, Moore JB, Kaczynski AT, Barr-Anderson DJ, Tate DF. Comparison of traditional versus mobile app selfmonitoring of physical activity and dietary intake among overweight adults participating in an mHealth weight loss program. J Am Med Inform Assoc. 2013;20:513-8.

4. NSCA's guide to tests and assessments 1 edition By National Strength \& Conditioning Association (U.S.). Todd Miller, editor. 2012. Human Kinetics.

5. Antonio J, Ellerbroek A, Silver T, Orris S, Scheiner M, Gonzalez A, et al. A high protein diet $(3.4 \mathrm{~g} / \mathrm{kg} /$ day $)$ combined with a heavy resistance training program improves body composition in healthy trained men and women-a follow-up investigation. J Int Soc Sports Nutr. 2015;12:39.

6. Teske JA, Billington CJ, Kotz CM. Neuropeptidergic mediators of spontaneous physical activity and non-exercise activity thermogenesis. Neuroendocrinology. 2008:87:71-90

7. Levine JA, Vander Weg MW, Hill JO, Klesges RC. Non-exercise activity thermogenesis: the crouching tiger hidden dragon of societal weight gain. Arterioscler Thromb Vasc Biol. 2006;26:729-36.

8. Swaminathan R, King RF, Holmfield J, Siwek RA, Baker M, Wales JK. Thermic effect of feeding carbohydrate, fat, protein and mixed meal in lean and obese subjects. Am J Clin Nutr. 1985:42:177-81.

9. Binns A, Gray M, Di Brezzo R. Thermic effect of food, exercise, and total energy expenditure in active females. J Sci Med Sport. 2015;18:204-8.

10. Chaumontet C, Even PC, Schwarz J, Simonin-Foucault A, Piedcoq J, Fromentin $\mathrm{G}$, et al. High dietary protein decreases fat deposition induced by high-fat and high-sucrose diet in rats. $\mathrm{Br} J$ Nutr. 2015;114:1132-42

11. Grooms KN, Ommerborn MJ, Pham DQ, Djousse L, Clark CR. Dietary fiber intake and cardiometabolic risks among US adults, NHANES 1999-2010. Am J Med. 2013;126:1059-67. e1051-1054.

12. German AJ, Holden SL, Bissot T, Morris PJ, Biourge V. A high protein high fibre diet improves weight loss in obese dogs. Vet J. 2010;183:294-7.

13. Lairon D, Arnault N, Bertrais S, Planells R, Clero E, Hercberg S, et al. Dietary fiber intake and risk factors for cardiovascular disease in French adults. Am J Clin Nutr. 2005;82:1185-94.

14. Fernandez ML, Calle M. Revisiting dietary cholesterol recommendations: does the evidence support a limit of $300 \mathrm{mg} /$ day? Curr Atheroscler Rep. 2010;12:377-83.

15. Utter AC, Goss FL, Swan PD, Harris GS, Robertson RJ, Trone GA. Evaluation of air displacement for assessing body composition of collegiate wrestlers. Med Sci Sports Exerc. 2003;35:500-5.
16. Harrison GG, Galal OM, Ibrahim N, Khorshid A, Stormer A, Leslie J, et al. Underreporting of food intake by dietary recall is not universal: a comparison of data from egyptian and american women. J Nutr. 2000;130:2049-54.

17. Novotny JA, Rumpler WV, Riddick H, Hebert JR, Rhodes D, Judd JT, et al. Personality characteristics as predictors of underreporting of energy intake on 24-h dietary recall interviews. J Am Diet Assoc. 2003;103:1146-51.
Submit your next manuscript to BioMed Central and we will help you at every step:

- We accept pre-submission inquiries

- Our selector tool helps you to find the most relevant journal

- We provide round the clock customer support

- Convenient online submission

- Thorough peer review

- Inclusion in PubMed and all major indexing services

- Maximum visibility for your research

Submit your manuscript at www.biomedcentral.com/submit
Biomed Central 